\title{
ANALISIS HAZARD IDENTIFICATION, RISK ASSESMENT AND RISK CONTROL (HIRARC) PADA PEKERJA INFORMAL PABRIK DIMSUM PERTOK PONDOK RANJI TAHUN 2020
}

\author{
Najla Nur Salsabila ${ }^{1}$, Dihartawan ${ }^{2}$, Nazarwin Saputra ${ }^{3}$ \\ 1,2,3 Program Studi Kesehatan Masyarakat, Fakultas Kesehatan Masyarakat, \\ Universitas Muhammadiyah Jakarta \\ Email : najlaansb82@gmail.com, dihartawan@umj.ac.id,nazarwin.saputra@gmail.com
}

\begin{abstract}
ABSTRAK
Keselamatan dan Kesehatan Kerja merupakan aspek penting dalam upaya meningkatkan kesejahteraan serta produktivitas pekerja. Apabila keselamatan kerja rendah, maka hal tersebut akan memberikan pengaruh buruk terhadap kesehatan sehingga berakibat pada produktivitas yang akan menurun. Peneliti telah melakukan studi pendahuluan untuk melihat gambaran awal terkait dengan kondisi yang ada dilapangan, terutama dalam Identifikasi bahaya (Hazard Identification), Penilaian Risiko (Risk Assesment), Pengendalian Risiko (Risk Control) pada Pabrik produksi Dimsum Pertok di daerah Pondok Ranji. Hasil yang perlu diamati yaitu instruksi kerja atau proses tahapan kerja. Dari bagian instruksi kerja, kemudian melakukan wawancara terkait kecelakaan kerja yang sering terjadi pada proses kerja tersebut. Jenis penelitian ini adalah penelitian mix methods, yaitu metode yang menggabungkan antara kuantitatif dan kualitatif. Penggabungan metode ini dilakukan secara bersamaan. Penelitian ini akan melakukan identifikasi bahaya dan pengendalian risiko sebagai penelitian kualitatif dan penilaian risiko sebagai penelitian kuantitatif. Berdasarkan wawancara dan observasi yang dilakukan oleh peneliti, terdapat beberapa potensi bahaya, hasil penilaian risiko yang dilakukan peneliti di Pabrik Dimsum Pertok Pondok Ranji, tingkat risiko low atau rendah yaitu pada proses pencucian dan pensortiran, pembuatan dimsum manual, pengukusan dimsum, dan pengangkatan dimsum dari alat pengukus dan packing. Tingkat risiko moderate atau sedang terdapat pada proses penggilingan bahan baku dan proses pengukusan. Kesimpulan dari penelitian ini adalah terdapatnya bahaya dari setiap proses kerja dengan penilaian risiko dan pengendalian risiko yang berbeda.
\end{abstract}

Kata Kunci : HIRARC, Informal 


\section{ABSTRACT}

Occupational safety and health are important aspects in efforts to improve worker welfare and productivity. If the work safety is low, then it will have a bad effect on health, resulting in decreased productivity. Researchers have conducted a preliminary study to see an initial picture related to the conditions in the field, especially in Hazard Identification, Risk Assessment, Risk Control at the Dimsum Pertok production plant in the Pondok Ranji area. The results that need to be observed are work instructions or work stages. From the work instructions section, then conduct interviews related to work accidents that often occur in the work process. This type of research is mix methods, which is a method that combines quantitative and qualitative methods. Combining these methods is carried out simultaneously. This research will identify hazards and risk control as qualitative research and risk assessment as quantitative research. Based on interviews and observations conducted by researchers, there are several potential hazards, the results of the risk assessment carried out by researchers at the Pondok Ranji Dimsum Factory, the low or low risk level, namely in the washing and sorting process, manual dim sum manufacturing, dim sum steaming, and dim sum removal from steamer and packing. The risk level is moderate or moderate in the milling process of raw materials and the steaming process. The conclusion of this study is that there is a danger in each work process with a different risk assessment and risk control.

Keywords : HIRARC, Informal

\section{LATAR BELAKANG}

Undang-Undang No.1 Tahun 1970 menyatakan setiap tempat kerja dimana terdapat adanya pekerja, memiliki sumber-sumber bahaya. Setiap pekerjaan selalu mengandung potensi bahaya yang mengakibatkan kecelakaan kerja. Kemungkinan kecelakaan dan penyakit akibat kerja tergantung pada jenis produksi, teknologi yang digunakan, bahan yang digunakan, struktur ruang dan lingkungan bangunan, dan kualitas manajemen personel pelaksana (Infodatin Kesehatan Kerja, 2015).

Berdasarkan laporan yang dikeluarkan oleh Organisasi Perburuhan Internasional (ILO), 2,78 juta pekerja meninggal setiap tahun karena kecelakaan kerja dan penyakit akibat kerja. Sekitar 2,4 juta $(86,3 \%)$ dari kematian ini disebabkan oleh penyakit akibat kerja, dan lebih dari 380.000 (13,7\%) disebabkan oleh kecelakaan di tempat kerja. Setiap tahun, ada hampir seribu kali lebih banyak kecelakaan kerja non-fatal daripada kecelakaan kerja fatal. Diperkirakan bahwa 374 juta pekerja mengalami kecelakaan fatal setiap tahun, banyak di antaranya telah sangat memengaruhi kapasitas penghasilan pekerja (International Labour Organization, 2018). Jumlah kasus kecelakaan kerja di Indonesia masih tinggi. Menurut data dari Organisasi Jaminan Sosial (BPJS), jumlah kecelakaan terkait pekerjaan terus meningkat. Pada tahun 2016, terdapat 105.182 kasus (26,2\%). Pada tahun 2017, jumlah kecelakaan industri yang dilaporkan terus meningkat menjadi 123.041 (30,7\%), sedangkan pada 2018 mencapai 173.105 (43.13\%). Menteri Ketenagakerjaan, Ida Fauziyah dalam acara Bulan Kesehatan dan Keselamatan Kerja (K3) tahun 2020 mengatakan kecelakaan kerja di Banten mengalami penurunan selama 
2019. Pada 2018 telah terjadi 157.313 kasus kecelakaan kerja, sementara sepanjang Januari hingga September 2019 terdapat 130.923 kasus. Hal ini menunjukkan terjadinya penurunan kasus kecelakaan kerja sebesar $26.40 \%$. Untuk mengurangi kecelakaan kerja, diperlukan adanya pengendalian terhadap sumber-sumber bahaya dan potensi bahaya yang ada di tempat kerja, karenanya sumber dan potensi bahaya tersebut harus ditemukan. Untuk mendapatkan dan menentukan adanya bahaya potensial yang dapat mengakibatkan kecelakaan dan penyakit akibat kerja, maka perlu diadakan identifikasi sumber bahaya potensial yang ada di tempat kerja. Setelah sumber dan potensi bahaya teridentifikasi, selanjutnya dilakukan evaluasi tingkat risiko sumber bahaya terhadap tenaga kerja (Febriana, 2010).

Peneliti telah melakukan studi pendahuluan untuk melihat gambaran awal terkait dengan kondisi yang ada dilapangan, terutama dalam Identifikasi bahaya (Hazard Identification), Penilaian Risiko (Risk Assesment), Pengendalian Risiko (Risk Control) pada Pabrik produksi Dimsum Pertok di daerah Pondok Ranji. Hasil yang perlu diamati yaitu instruksi kerja atau proses tahapan kerja. Dari bagian instruksi kerja, kemudian melakukan wawancara terkait kecelakaan kerja yang sering terjadi pada proses kerja tersebut. Tujuan dari adanya Observasi ini yaitu untuk memperoleh informasi mengenai Hazard Identification Risk Assessment Risk Control (HIRARC) pada pekerja Informal yang tidak banyak diketahui oleh masyarakat. Setelah informasi tersebut didapatkan, maka peneliti bermaksud untuk mengangkat hal tersebut menjadi skripsi sehingga mampu dipertimbangkan oleh pengusaha mengenai Kesehatan dan Keselamatan Kerja.

Penelitian ini dilakukan pada usaha informal home industri Dimsum Pertok di daerah Pondok Ranji. Hasil observasi awal yang dilakukan penulis bersama dengan pemilik usaha /sebagai studi pendahuluan ini merupakan kegiatan yang menghasilkan Instruksi kerja, Riwayat Kecelakaan selama 4 bulan terakhir, mengetahui bahaya diarea kerja, Risiko, hingga upaya pengendalian dalam setiap proses pekerjaan. Observasi difokuskan pada pelaksaan penerapan Keselamatan dan kesehatan kerja dengan menggunakan metode wawancara kepada Pemilik usaha yang berada di pabrik tersebut.

Peneliti telah melakukan wawancara bersama pemilik usaha, pemilik menjelaskan adapun riwayat Kecelakaan yang terdapat pada usaha dimsum yaitu tangan yang tergores pisau saat memotong ayam, tangan terjepit alat penggilingan, tangan terkena panas alat kukus, hingga bagian badan yang sering sakit dikarenakan posisi duduk yang salah saat membuat dimsum yang terus menerus, dari hasil wawancara tersebut, dapat dikatakan kecelakaan mungkin terjadi setiap hari, yang dapat disimpulkan bahwa ada bahaya yang terjadi di pabrik dimsum yang dapat menimbulkan risiko hingga kecelakaan. Risiko merupakan dampak atau kerugian yang disebabkan dari bahaya yang terdapat dalam suatu proses kerja. Jika dibiarkan terus menerus terjadi dapat mengakibatkan berkurangnya produktivitas pekerja dan menurunkan hasil produksi yang dapat merugikan pemilik usaha.

Berdasarkan hasil studi pendahuluan yang telah dilakukan oleh peneliti, perlu dilakukannya penilaian lebih lanjut dari kejadian kecelakaan kerja yang berada di pabrik Dimsum Pertok, agar pekerja mengetahui bahaya dan risiko yang ada pada pekerjaan mereka selama bekerja di Pabrik sebagai upaya pengendalian dan juga pencegahan kecelakaan kerja. Berdasarkan hal tersebut penulis akan melakukan penelitian dan menganalisis tentang "Hazard Identification, Risk Assessment, Risk Control pada pekerja Pabrik Dimsum Pertok Pondok Ranji pada tahun 2020”. 


\section{METODE PENELITIAN}

Jenis penelitian ini adalah penelitian mix methods, yaitu metode yang menggabungkan antara kuantitatif dan kualitatif. Penggabungan metode ini dilakukan secara bersamaan. Penelitian ini akan melakukan identifikasi bahaya dan pengendalian risiko sebagai penelitian kualitatif dan penilaian hasil.

\section{HASIL DAN PEMBAHASAN}

Hasil dari Hazard identification / identifikasi bahaya yang terdapat pada pekerja informal Pabrik Dimsum Pertok Ranji yang dilakukan dengan pengambilan data menggunakan pedoman wawancara, memuat hasil seperti yang terlihat pada tabel 1 .

Hasil dari identifikasi bahaya dan risiko yang telah di dapatkan pada Pabrik Dimsum Pertok Pondok Ranji, selanjutnya dilakukan penghitungan risiko agar mengetahui risk level dengan kategori $\mathrm{L}=$ Low, $\mathrm{M}=$ Moderate, $\mathrm{H}=$ High, dan $\mathrm{E}=$ Ekstreme. Pengambilan data berdasarkan pedoman wawancara dengan berasas pada AN/NZS:2004, memuat hasil sebagaimana dapat dilihat pada tabel 2.

\section{Tabel 1}

Penilaian Risiko

\begin{tabular}{ll}
\hline Risiko & Persentase \\
\hline Gangguan sendi dan otot & $10 \%$ \\
Penyakit kulit & $10 \%$ \\
Luka goresan, memar, cidera & $30 \%$ \\
Efek kejut listrik & $10 \%$ \\
Gangguan sendi & $20 \%$ \\
Luka bakar & $20 \%$ \\
\hline & $100 \%$ \\
\hline
\end{tabular}

Sumber: Penelitian primer 2020

Tabel 2

Hasil Hazard Identification / Identifikasi Bahaya pada pekerja informal Pabrik Dimsum Pertok Pondok Ranji

\begin{tabular}{|c|c|c|}
\hline Kegiatan & Potensi Bahaya & Risiko \\
\hline $\begin{array}{l}\text { Pencucian dan } \\
\text { pensortiran bahan baku }\end{array}$ & Terpeleset & $\begin{array}{l}\text { Gangguan sendi dan otot } \\
\text { Kaki terkena penyakit kulit } \\
\text { infeksi jamur atau kutu air }\end{array}$ \\
\hline Penggilingan & $\begin{array}{l}\text { Tangan tergiling mesin } \\
\text { Tersengat listrik }\end{array}$ & $\begin{array}{l}\text { Luka goresan } \\
\text { Efek kejut listrik }\end{array}$ \\
\hline $\begin{array}{l}\text { Pembuatan dimsum } \\
\text { manual }\end{array}$ & Sakit pinggang & $\begin{array}{l}\text { Gangguan sendi dan otot } \\
\text { tulang belakang }\end{array}$ \\
\hline Pengukusan & $\begin{array}{l}\text { Tergores alat pengukus panas, } \\
\text { wajah terkena uap panas saat } \\
\text { membuka tutup alat pengukus } \\
\text { Tabung gas bocor atau meledak }\end{array}$ & Luka goresan atau luka bakar \\
\hline $\begin{array}{l}\text { Pengangkatan dimsum } \\
\text { dari alat pengukus dan } \\
\text { packing }\end{array}$ & $\begin{array}{l}\text { Tergores alat pengukus panas, } \\
\text { loyang dimsum panas terjatuh } \\
\text { terkena kaki pekerja }\end{array}$ & Luka goresan dan memar \\
\hline
\end{tabular}


Berdasarkan tabel 1 hasil penelitian yang diperoleh dari penilaian risiko yang beracuan pada potensi bahaya pada setiap kegiatan di Pabrik Dimsum Pertok Pondok Ranji dengan 6 responden, persentasi tertinggi yaitu sebesar 30\% dengan risiko luka goresan, memar, dan cidera, 20\% gangguan sendi dan luka bakar, dan persentasi merata dari gangguan sendi dan otot, penyakit kulit, dan efek kejut listrik sebesar $10 \%$.

Berdasarkan hasil dari potensi bahaya yang telah di dapat, terdapat risiko yang mungkin akan di derita oleh pekerja yaitu:

1. Pada bagian pencucian dan pensortiran bahan baku terdapat potensi bahaya fisik dari lantai yang basah dan licin, yang dapat mengakibatkan pekerja terjatuh atau terpeleset dan menyebabkan gangguan sendi atau otot dan dalam jangka waktu yang panjang dapat menyebabkan penyakit kulit kutu air di kaki pekerja.

2. Pada proses penggilingan, terdapat bahaya fisik dan bahaya listrik. Pekerja sering mengabaikan keselamatan yaitu dengan memasukan tangan ke dalam mesin penggilingan agar proses berjalan lebih cepat. Hal ini menyebabkan risiko tangan pekerja tergiling mesin dan robekdan terluka. Bahaya listrik juga mungkin terjadi jika pekerja tidak memperhatikan tangan dalam keadaan basah atau kering.

3. Bahaya ergonomi terdapat pada proses pembuatan dimsum secara manual. Pekerja duduk selama 8 jam lebih setiap hari nya dengan posisi duduk yang kurang baik kursi yang tidak memiliki sanggahan sehingga menyebabkan sakit pinggang. Dan jika dalam jangka waktu yang panjang akan menyebabkan penyakit gangguan sendi dan otot yang serius.

4. Pada proses pengukusan dimsum bahaya yang ada yaitu baya fisik dari panci pengukusan yang sudah panas, risiko yang dapat terjadi yaitu tangan tergores alat pengukus yang panas dan menyebabkan luka bakar, wajah terkena uap panas saat membuka tutup alat pengukus. Bahaya lainnya yaitu bahaya dari tabung gas yang mungkin berpotensi bocor atau meledak.

5. Pada proses pengangkatan dimsum dan packing bahaya yang mungkin terjadi yaitu bahaya fisik dari panci pengukusan yang panas, pekerja sering tergores alat pengukus panas jika tidak memperhatikan keselamatan. Loyang dimsum panas terjatuh terkena kaki pekerja.

Hasil dari penilaian risiko kemudian dilakukan penetapan pengendalian yang bertujuan untuk memberikan tindak lanjut dari nilai yang telah di dapat, penetapan pengendalian didapatkan dengan menggunakan wawancara mendalam kepada pekerja, dan kemudian, hasil dari penetapan pengendalian didiskusikan kepada pemilik usaha untuk dijadikan penanggung jawab dalam proses pelaksanaan upaya kesehatan dan keselamatan kerja.

Berdasarkan hasil penelitian yang diperkuat oleh hasil wawancara dengan pekerja dalam setiap bagian untuk mengetahui penetapan pengendalian, ada beberapa tahapan yang menjadi perhatian bagi peneliti yaitu pada tahap pencucian dan penyortiran bahan baku, tahap penggilingan, tahap proses pembuatan dimsum secara manual, tahap pengukusan dimsum, serta tahap pengangkatan dimsum setelah dikukus.

Penyusunan HIRARC diawali dengan meminta persetujuan kepada para ahli untuk memenuhi keabsahan data alam validasi konstruk, hal tersebut dilakukan untuk menjamin bahwa formulir HIRARC sudah memenuhi asa-asas kesehatan dan keselamatan kerja secara akademik, penggunaan bahasa, dan juga realitas dalam dunia kerja. Bukti dari pernyataan keabsahan HIRARC dilampirkan dalam lampiran. HIRARC merupakan salah satu persyaratan yang harus ada dalam menerapkan SMK3 berdasarkan 
OHSAS 18001:2007, Klausal 4.3.1 pada OHSAS 18001:2007 mengharuskan organisasi/perusahaan yang akan menerapkan SMK3 berdasarkan OHSAS 18001:2007 melakukan penyusunan HIRARC pada perusahaannya. HIRARC dibagi menjadi 3 tahap yaitu identifikasi bahaya (hazard identification), penilaian risiko (risk assessment), dan pengendalian risiko (risk control). (OHSAS 18001:2007).

Pabrik Dimsum Pertok belum menerapkan standar keselamatan dan kesehatan kerja dalam bekerja secara baik, termasuk dalam melakukan upaya identifikasi bahaya dan penilaian risiko serta menentukan pengendalian yang mampu menurunkan angka kecelakaan ditempat kerja, berikut merupakan tahapan dalam penyusunan HIRARC. Undang-Undang No.1 Tahun 1970 menyatakan setiap tempat kerja baik di ruangan atau lapangan, tertutup atau terbuka, bergerak, atau tetap dimana tenaga kerja bekerja, atau sering dimasuki pekerja untuk keperluan suatu usaha memiliki sumber-sumber bahaya bagi pekerjanya. Identifikasi bahaya adalah upaya untuk mengetahui, mengenal, dan memperkirakan adanya bahaya pada suatu sistem, seperti peralatan, tempat kerja, proses kerja, dan prosedur (Safety Sign Indonesia, 2018).

Dari 5 tahapan kerja dalam proses produksi dimsum, teridentifikasi enam sumber bahaya diantaranya gangguan sendi dan otot, penyakit kulit, luka goresan, memar, dan cidera, efek kejut listrik, gangguan sendi dan luka bakar. Dimana masing-masing sumber bahaya memiliki potensi bahaya berupa bahaya fisik dan ergonomi. Keberadaan potensi bahaya tersebut dapat mengakibatkan terjadinya kecelakaan atau insiden yang berdampak terhadap manusia. Risiko menggambarkan besarnya potensi bahaya tersebut untuk dapat menimbulkan insiden atau cedera pada manusia yang ditentukan oleh kemungkinan atau keparahannya yang diakibatkannya.

Risiko tersebut kemudian dianalisa berdasarkan observasi dan wawancara dengan pekerja terkait peralatan yang digunakan, bahan, dan proses kerja untuk melihat seberapa besar potensi bahaya yang dapat menimbulkan konsekuensi bagi pekerja. Risiko ini dinilai dan dikelompokkan kedalam beberapa tingkatan risiko / risk level.

Hasil penelitian tersebut selaras dengan hasil penelitian yang telah dilakukan oleh Rina Mustika, dkk tahun 2019 di Batik Tulis Sri Kuncoro Imogiri Barat Yogyakakarta, setiap aktivitas pekerjaan membatik memiliki potensi bahaya. Penggunaan alat / mesin menimbulkan bahaya mekanis, ketika pot dan wajan yang terbuat dari tembaga pada lilin atau kain Khmer jatuh pada pekerja, itu akan menyebabkan abrasi. Bahaya fisik, yaitu, suhu di malam hari terkena tetesan lilin, suhu pot, suhu tetesan air, dan suhu yang dihasilkan oleh sinar matahari, yang akan menyebabkan kulit melepuh dan membakar kulit. Bahan yang digunakan dalam proses akan menyebabkan bahaya kimia dan pewarnaan, yaitu Karena pewarna tekstil, naphthol dan indophenol memiliki risiko iritasi dan gatal-gatal, dan bahkan menyebabkan kanker kulit dan bahaya ergonomis, yaitu, penggunaan kursi yang tidak ergonomis dapat menyebabkan penyakit muskuloskeletal bagi pekerja. risiko.Semua bahaya dan risiko yang didapatkan akan mengakibatkan pekerja dapat mengalami rasa kurang nyaman dalam melakukan aktivitas sehari-hari, merasa tidak bebas melakukan aktivitasnya, mengalami cidera ringan/berat, keruguan materi dan kehilangn hari kerja. Menurut Tarwaka bahaya ditempat kerja timbul atau terjadi ketika ada interaksi antara unsur-unsur produksi yaitu manusia, peralatan, material, proses atau metode kerja.

Penelitian yang dilakukan oleh Intan Karundeng, dkk yang berjudul Analisis Bahaya dan Risiko dengan Metode HIRARC di Departmen Production PT. Samudera Mulia Abadi Mining Contractor Likupang Minahasa Utara mendukung keselarasan dari penelitian yang sedang dilakukan, hal ini terlihat dari hasil terkait. Identifikasi bahaya 
yang memuat adanya bahaya yaitu diantaranya tabrakan antar unit, vessel ADT terserunduk oleh excavator, landasan yang tidak sesuai tergelincir, dan terkena lentingan batu dengan resiko kecelakaan terbalik, rebah, terguling, terjepit, dan operator dapat terkena lentingan batu.

Berdasarkan penelitian Rizkya (2018) selaras dengan penelitian ini, yang memaparkan penanganan sikap kerja pada operator yang bekerja dalam posisi berdiri dan membungkuk. Aktivitas kerja yang dilakukan oleh operator ini dapat dipengaruhi oleh gangguan, rasa sakit, kekakuan, dan ketidaknyamanan. Pekerja dengan penyakit muskulo-skeletal ditemukan dari laporan pekerja yang mengeluh sakit. Ini menunjukkan perlunya menetapkan undang-undang tentang ergonomi dan meningkatkan fasilitas kerja untuk mencegah pekerja mengembangkan penyakit muskuloskeletal.

OHSAS 18001:2007 dalam isinya menyebutkan setiap perusahaan harus membuat, menerapkan, dan memelihara prosedur untuk mengidentifikasi bahaya dari setiap kegiatan yang ada, penilaian resiko, dan menetapkan pengendalian yang diperlukan. Berdasarkan hasil penilaian resiko tersebut kita dapat mengidentifikasi atau menentukan tindakan yang akan kita lakukan terhadap setiap resiko. Potensi bahaya yang ditemukan pada tahap identifikasi bahaya akan dilakukan penilaian risiko guna menentukan tingkat risiko (risk rating) dari bahaya tersebut. Penilaian risiko dilakukan dengan berpedoman pada skala Australian Standard/New Zealand Standard for Risk Management (AS/NZS 4360:2004). Ada 2 parameter yang digunakan dalam penilaian risiko, yaitu probability dan severity.

Berdasarkan hasil penilaian risiko dari proses tahapan kerja di Pabrik Dimsum Pertok, pada proses pencucian dan pensortiran bahan baku terdapat risiko pekerja terpeleset penilaian risiko yaitu nilai peluang terjadinya atau probability adalah 3 (mungkin terjadi) dikalikan dengan nilai keparahan atau severity yaitu 3 (cidera sedang) dan menghasilkan jumlah 9 yang berarti memiliki tingkat risiko moderate atau sedang. Sedangkan Pada risiko kaki terkena penyakit kulit kutu air penilaian risiko yang didapat yaitu probability adalah 2 (jarang terjadi) di kalikan dengan nilai keparahan atau severity yaitu 2 (cidera ringan) dan menghasilkan nilai 4 yang berarti memiliki tingkat risiko low atau rendah. Pada proses penggilingan berdasarkan penilaian risiko yang dilakukan oleh peneliti, didapatkan nilai probability yaitu 2 (jarang terjadi) dan dikalikan dengan nilai keparahan atau severity yaitu 4 (cidera berat) dan menghasilkan nilai 4 yang memiliki arti tingkat risiko moderate atau sedang. Pada proses pembuatan dimsum secara manual dari hasil penilaian risiko yang dilakukan peneliti nilai probability yaitu 4 (sering terjadi) dikalikan dengan severity yaitu 1 (luka tidak berarti) menghasilkan nilai 4 yang berarti Low atau rendah. Pada proses pengukusan dimsum peneliti telah melakukan penilaian risiko yaitu dari risiko luka goresan atau luka bakar didapatkan nilai probability yaitu 4 (sering terjadi) dikalikan dengan severity yaitu 1 (luka tidak berarti) menghasilkan nilai 4 yang berarti Low atau rendah. Potensi risiko dari tabung gas bocor memiliki penilaian risiko yaitu nilai probability yaitu 1 (sangat jarang terjadi) dikalikan dengan severity yaitu 5 (fatality) menghasilkan nilai 5 yang berarti memiliki tingkat risiko Moderate atau sedang. Dari proses pengangkatan dimsum telah dilakukan penilaian risiko yaitu dari risiko luka goresan atau luka bakar didapatkan nilai probability yaitu 4 (sering terjadi) dikalikan dengan severity yaitu 1 (luka tidak berarti) menghasilkan nilai 4 yang berarti Low atau rendah.

Penelitian ini sejalan dengan penelitian yang dilakukan di oleh Andelia, Natasya (2018) di Pabrik Pembuatan Dodol Kentang dengan risiko tersengat aliran listrik dan terjadinya korsleting listrik dapat berakibat cukup serius risiko ini hampir tidak pernah 
terjadi, namun tingkat keparahannya tergolong moderate atau dapat menyebabkan cedera sedang dan memerlukan penanganan medis.

Hasil penelitian yang telah dilakukan oleh Rina Mustika, dkk tahun 2019 di Batik Tulis Sri Kuncoro Imogiri Barat Yogyakakarta selaras dengan penelitian yang sedang dilakukan, yaitu seluruh proses produksi pembuatan batik ditemukan 2 aktivitas pekerjaan yang memiliki risiko tinggi (high risk) yaitu penempelan lilin malam dan pencelupan, 3 aktivitas pekerjaan yang memiliki risiko menengah (moderate risk) yaitu pola batik, pelorodan lilin malam dan persiapan bahan pewarnaan dan 3 aktivitas pekerjaan yang memiliki risiko rendah (low risk) yaitu persiapan bahan/alat, angkat angkut kain batik, dan penjemuran.

Penelitian yang dilakukan oleh Intan Karundeng, dkk yang berjudul Analisis Bahaya dan Risiko dengan Metode HIRARC di Departmen Production PT. Samudera Mulia Abadi Mining Contractor Likupang Minahasa Utara mendukung keselarasan dari penelitian yang sedang dilakukan, hal ini terlihat dari hasil terkait risk assessment / penilaian risiko yang mendapatkan bahaya dan resiko pada proses pengoprasian unit ADT di area loading point dengan peringkat resiko sebagai berikut : (1) Ruang gerak terbatas potensi bahaya collision (tabrakan) dengan resiko ADT dapat terbalik, rebah, dan terguling, termasuk pada peringkat resiko tinggi dengan penentuan tingkat resiko berdasarkan perhitungan : keparahan (severity) dari resiko ini level 3 (moderate) karena pekerja dapat mengalami luka sedang dan memar pada bagian tangan dan kaki dan kemungkinan (likelihood) dari resiko ini level 4 (likely) karena kecelakaan ini terjadi beberapa kali dalam 1 bulan. (2) Posisi yang tidak tepat saat loading, potensi bahaya tabrakan antar unit ADT dan Excavator dan terkena lentingan batu dari proses loading material denga resiko ADT terbalik, kerusakaan unit, termasuk pada peringkat resiko tinggi dengan penentuan tingkat resiko berdasarkan perhitungan : keparahan (severity) dari resiko ini level 3 (moderate) karena pekerja dapat mengalami luka ringan dan memar pada bagian tangan dan kaki, kepala terbentur dan kemungkinan (likelihood) dari resiko ini level 4 (likely) karena kecelakaan ini terjadi beberapa kali dalam 1 bulan. (3) Area loading dan dumping yang tidak stabil, potensi bahaya ADT tergelincir (slippery) termasuk pada peringkat resiko sedang dengan penentuan tingkat resiko berdasarkan perhitungan : keparahan (severity) dari resiko ini level 2 (minor) karena berdampak luka ringan dan kemungkinan (likelihood) dari resiko ini level 3 (Possible) karena kecelakaan ini dapat terjadi sesekali atau sebulan.(4) Mengoprasikan di luar prosedur, potensi bahaya menabrak atau ditabrak, tergelincir dengan resiko ADT terbalik, terguling termasuk pada peringkat resiko sedang dengan penentuan tingkat resiko berdasarkan perhitungan : keparahan (severity) dari resiko ini level 3 (moderate) karena berdampak luka ringan dan kemungkinan (likelihood) dari resiko ini level 2(unlikely) karena kecelakaan ini terjadi jarang atau dalam setahun.(5) Tidak konsentrasi, potensi bahaya menabrak beresiko terbalik, rebah termasuk pada peringkat resiko sedang dengan penentuan tingkat resiko berdasarkan perhitungan : keparahan (severity) dari resiko ini level 3 (moderate) karena berdampak luka ringan dan kemungkinan (likelihood) dari resiko ini level 2 (unlikely) karena kecelakaan ini terjadi jarang atau dalam setahun. (6) Kurangnya pengetahuan dan skill potensi bahaya tabrakan, beresiko terbalik, rebah, tergelincir termasuk pada peringkat resiko ringan dengan penentuan tingkat resiko berdasarkan perhitungan: keparahan (severity) dari resiko ini level 2 (minor) karena berdampak luka ringan dan kemungkinan (likelihood) dari resiko ini level 1 (rare) karena kecelakaan ini hamper tidak pernah terjadi. 
Pengendalian resiko dalam setiap proses pada pembuatan dimsum dilakukan agar dampak atau insiden yang mungkin terjadi tidak lebih besar tingkat resikonya. Rekomendasi yang dilakukan tentunya selain mengurangi tingkat resiko kecelakaan tentunya juga mencegah turunnya produktivitas kerja pekerja yang ada.

Berdasarkan hasil penelitian, dalam tahapan pencucian dan penyortiran peneliti menemukan pengendalian risiko yaitu pekerja harus membersihkan lantai setelah mencuci dan menyortir bahan baku agar lantai tidak licin, dan memasang keset anti slip dilantai pencucian serta pekerja memakai APD berupa sepatu boot. Pada proses penggilingan ini terdapat risiko tangan pekerja terluka goresan, hingga tergiling mesin. Bahaya listrik juga mungkin terjadi jika pekerja tidak memperhatikan tangan dalam keadaan basah atau kering. Pengendalian risiko dapat berupa arahan cara kerja aman dari pemilik usaha sebelum memulai pekerja seperti selalu mengingatkan pentingnya keselamatan dan menghindarkan hal yang dapat menyebabkan kecelakaan selama bekerja. Pemilik usaha juga harus selalu mengingatkan pekerja pada bagian penggilingan agar memerhatikan kondisi basah atau keringnya tangan pekerja agar tidak terjadi kecelakaan kerja dari sumber bahaya listrik. Pada proses pembuatan dimsum secara manual pengendalian risiko yang dapat dilakukan yaitu pemilik usaha mengatur shift kerja, dan mengganti kursi yang biasa digunakan dengan kursi yang dapat penyanggah badan pekerja. Pada proses pengukusan dimsum pengendalian yang dapat dilakukan yaitu pekerja mendapatkan arahan cara kerja aman dari pemilik usaha untuk memerhatikan keselamatan dan tidak ceroboh. Pekerja harus mengecek tabung gas secara rutin sebelum memulai bekerja. Pengendalian lainnya yaitu dengan menggunakan APD masker dan sarung tangan. Pada proses pengangkatan dimsum, pengendalian risiko yang dapat dilakukan yaitu pekerja mendapatkan arahan cara kerja aman dari pemilik usaha untuk memerhatikan keselamatan dan tidak ceroboh. Pengendalian lainnya yang dapat dilakukan yaitu pekerja menggunakan APD masker dan sarung tangan.

Penelitian yang dilakukan oleh Fatmawaty Mallapiang tentang Analisis Potensi Bahaya Dan Pengendalian Dengan Metode Industri Kelapa Sawit PT. Manakarra Unggul Lestari (PT. Mul) Pada Stasiun Digester dan Presser, Clarifier, Nut dan Kernel, Mamuju, Sulawesi Barat selaras dengan penelitian yang sedang dilakukan yaitu pada pengendalian risiko yang ada antara lain terjatuh, luka, pengendalian yang digunakan adalah pengendalian secara Eliminasi, berupa penghilangan sumber bahaya tetesan mintak pada lantai dan APD, yaitu sepatu safety. Luka bakar pengendalian yang digunakan adalah pengendalian secara Administratif, berupa pembuatan prosedur kerja sebagai bentuk kerja aman terhadap peralatan yang dioprasikan dan APD yaitu sarung tangan dalam pengoprasian mesin.

Berdasarkan penelitian yang dilakukan oleh Ade Irpan, dkk tahun 2019 yang berjdul Analisis Risiko Keselamatan dan Kesehatan Kerja di Home Industry pembuatan tempe di Kelurahan Badak Kecamatan Tanah Sarael Kota Bogor selaras dengan penelitian yang sedang dilakukan yaitu pada kegiatan pemindahan kacang ke mesin pemecah memiliki risiko tinggi tersetrum yang di sebabkan oleh Instalasi Listrik karena pekerja mencabut stop kontak listrik mesin pengupas kacang dengan kondisi tangan basah pada pekerja bagian pengupasan kacang yang berisiko terjadinya tersetrum. Proses ini belum ada pengendalian, adapun sarang pengendalain dengan cara Pengendalian secara substitusi dengan mengganti colokan menjadi stop kontak, Adminitrasi kontrol (mengeringkan tangan), Pengendalian menggunakan APD (sarung tangan).

Penelitian yang dilakukan oleh Tivany Edwin,dkk tahun 2019 tentang Analisis Risiko pada bagian produksi pabrik pengolah data getah karet menggunakan metode 
HIRARC yang berkaitan dengan pengendalian risiko selaras dengan penelitian yang dilakukan, yaitu upaya pengendalian yang disarankan pada pengolahan raw material antara lain berupa penggunaan Alat Pelindung Diri (APD) bagi operator serta karyawan yang bekerja pada area pembongkaran. Sebaiknya perusahaan melengkapi APD untuk para pekerja, sesuai yang diatur dalam PP No. 50 Tahun 2012 dalam elemen keamanan bekerja berdasarkan SMK3. Pada proses penjemuran blanket, perlu disediakan alat pemadam kebakaran pada tempat tumpukan kayu dan karet, karena berpotensi bahaya kebakaran, sedangkan pada proses penjemuran diharapkan karyawan selalu memakai sepatu safety agar dapat terhindar dari bahaya tergelincir. Selanjutnya pada bagian pengolahan blanket di dryer, operator disarankan memakai sepatu safety dan masker agar terhindar dari bahaya tergelincir dan menghirup bau tidak sedap, kemudian perlunya disediakan alat pemadam kebakaran pada pegoperasian burner, serta perlunya informasi tata cara kegiatan press agar tangan pekerja terhindar dari terkena alat press.

\section{SIMPULAN DAN SARAN \\ Simpulan}

Berdasarkan wawancara dan observasi yang dilakukan oleh peneliti, terdapat beberapa potensi bahaya yaitu lantai yang basah dan licin, mesin penggilingan yang tajam, bahaya listrik, sakit pinggang, tangan tergores alat pengukus panas, wajah terkena uap panas saat membuka tutup alat pengukus, tabung gas bocor atau meledak, tangan tergores alat pengukus panas dan loyang dimsum yang panas terjatuh. Berdasarkan hasil penilaian risiko yang dilakukan peneliti di Pabrik Dimsum Pertok Pondok Ranji, tingkat risiko low atau rendah yaitu pada proses pencucian dan pensortiran, pembuatan dimsum manual, pengukusan dimsum, dan pengangkatan dimsum dari alat pengukus dan packing. Tingkat risiko moderate atau sedang terdapat pada proses penggilingan bahan baku dan proses pengukusan. Pengendalian yang mungkin dilakukan untuk meminimalisir potensi bahaya di Pabrik Dimsum Pertok Pondok Ranji yaitu dengan pengendalian Eliminasi, pengendalian teknis, administrasi kontrolm dan APD.

\section{Saran}

Saran yang dapat dijadikan pertimbangan dalam pengambilan keputusan untuk upaya peningkatan kesehatan dan keselamatan pekerja di Pabrik Dimsum Pertok Pondok Ranji adalah:

1. Melaksanakan, menjaga, dan memperhatikan aspek kesehatan dan keselamatan sebagai upaya meminimalisir kecelakaan kerja

2. Pemilik usaha memperketat pengawasan terhadap pekerja selama proses kerja berlangsung

3. Memberikan sanksi teguran tegas kepada pekerja jika tidak memerhatikan aspek kesehatan dan keselamatan kerja

\section{DAFTAR PUSTAKA}

BPJSketenagakerjaan.go.id. (2019). Angka Kecelakaan Kerja Cenderung Meninfgkat, BPKS Ketenagakerjaan Bayar Santunan Rp. 1,2 Triliun https://www.bpjsketenagakerjaan.go.id/berita/23322/Angka-Kecelakaan-KerjaCenderung-Meningkat,-BPJS-Ketenagakerjaan-Bayar-SantunanRp1,2-Triliun Diakses pada tanggal 11 Mei 2020 Pukul 13.00 WIB.

Febriana, Y. (2010). Identifikasi Bahaya Dan Penialain Risiko Pada Proses Kerja di Area Whashing UT Reman Jakarta PT. United Tractor Tbk, Cakung Jakarta Timur. 
(41), 1-6.

ILO. (2018). Meningkatkan Keselamatan dan Kesehatan Pekerja Muda. International Labour Organization.

Kemnaker. (2020). Bulan Kesehatan dan Keselamatan Kerja (K3) Tahun 2020. https://kemnaker.go.id/news/binwasnaker-k3 diakses pada Tanggal 9 mei 2020 pukul 10.54 WIB.

Pusdatin Kemenkes RI. (2015). Infodatin pusat data dan informasi kementerian kesehatan RI Situasi Kesehatan Kerja.

Undang-Undang RI No. 1/1970 tentang Keselamatan Kerja. 